\title{
Scuticociliate infection and pathology in cultured turbot Scophthalmus maximus from the north of Portugal
}

\author{
Miguel Filipe Ramos ${ }^{1}$, Ana Rita Costa ${ }^{2}$, Teresa Barandela $^{2}$, Aurélia Saraiva ${ }^{1,3}$, \\ Pedro N. Rodrigues ${ }^{2,4, *}$ \\ ${ }^{1}$ CIIMAR (Centro Interdisciplinar de Investigação Marinha e Ambiental), Rua dos Bragas, 289, 4050-123 Porto, Portugal \\ ${ }^{2}$ ICBAS (Instituto de Ciências Biomédicas Abel Salazar), Largo Prof. Abel Salazar, 2, 4099-003 Porto, Portugal \\ ${ }^{3}$ FCUP (Faculdade de Ciências da Universidade de Porto), Praça Gomes Teixeira, 4099-002 Porto, Portugal \\ ${ }^{4}$ IBMC (Instituto de Biologia Molecular e Celular), Rua do Campo Alegre, 823, 4150-180 Porto, Portugal
}

\begin{abstract}
During the years 2004 and 2005 high mortalities in turbot Scophthalmus maximus (L.) from a fish farm in the north of Portugal were observed. Moribund fish showed darkening of the ventral skin, reddening of the fin bases and distended abdominal cavities caused by the accumulation of ascitic fluid. Ciliates were detected in fresh mounts from skin, gill and ascitic fluid. Histological examination revealed hyperplasia and necrosis of the gills, epidermis, dermis and muscular tissue. An inflammatory response was never observed. The ciliates were not identified to species level, but the morphological characteristics revealed by light and electronic scanning microscopes indicated that these ciliates belonged to the order Philasterida. To our knowledge this is the first report of the occurrence of epizootic disease outbreaks caused by scuticociliates in marine fish farms in Portugal.
\end{abstract}

KEY WORDS: Philasterida - Scuticociliatia - Histophagous parasite - Scophthalmus maximus · Turbot · Fish farm

Resale or republication not permitted without written consent of the publisher

\section{INTRODUCTION}

Scuticociliates (Ciliophora) are regarded as being scavengers that feed on suspended particulate matter (bacteria, microalgae, protozoa, etc.), which, under certain circumstances, can behave as opportunistic histophagous parasites, causing severe infections in marine fish and crustaceans in farms (Cawthorn 1997, Alvarez-Pellitero et al. 2004, Kim et al. 2004b) known as scuticociliatosis.

The presence of these ciliates in fish tissues has been associated with various pathological changes, including bleeding cutaneous ulcers, dystrophic and necrotic effects on muscles, hypocromic anaemia and encepha- litis; these changes are associated with the softening and liquefaction of brain tissues (Iglesias et al. 2001) and cause considerable mortalities in cultured fish. Although the natural route of entry into the host remains unknown, it has been suggested that natural infections occur via lesions in the skin or gills (Paramá et al. 2003).

During the last decade this disease has been recognised as one of the most important parasitological problems affecting cultured marine fish worldwide. A growing number of scuticociliatosis outbreaks have been reported from Spain (Dyková \& Figueras 1994, Iglesias et al. 2001), Norway (Sterud et al. 2000) and Korea (Jee et al. 2001, Kim et al. 2004a,b). 
There is no effective treatment for scuticociliatosis. Formalin baths can eliminate the parasite while it remains outside the host, but are ineffective once the ciliate is located inside the fish body (Iglesias et al. 2002).

The present paper reports on the occurrence of scuticociliosis during the years 2004 and 2005 in turbot from a fish farm grow-out facility located in the north of Portugal, where fish were held in a flow-through supply of seawater supplemented with oxygen in circular concrete tanks.

\section{MATERIALS AND METHODS}

Moribund specimens of turbot Scophthalmus maximus (L.) from several outbreaks in a grow-out facility in the north of Portugal were collected monthly from March 2004 to February 2005 in order to determine the disease that caused the progressive mortalities. The fish present in the fish farm (under $300 \mathrm{~g}$ ) were sampled and examined for lesions. Squash smears from different organs and tissues (including gills, skin, ascitic fluid and blood obtained from the caudal vein) were visualised by light microscopy.

For histological studies, samples of several organs and tissues (skin, gills, brain, heart, spleen, liver, kidney and intestine) were fixed in $10 \%$ phosphatebuffered formalin, routinely processed, sectioned (3 $\mu \mathrm{m}$ thick), stained with haematoxylin and eosin (H\&E) and examined under the light microscope.

For scanning electron microscopy (SEM), ciliates from mucus were concentrated by centrifugation (1500 rpm, $800 \times g$, for $2.5 \mathrm{~min}$ ) fixed in $2.5 \%$ gluteraldehyde in cacodylate buffer, post-fixed in $2 \%$ osmium tetroxide, dehydrated through an ethanol series, critical-point dried, coated with gold and examined in a Joel JMS 6301F scanning electron microscope.

\section{RESULTS}

Mortalities occurred throughout the entire study period, being particularly heavy during May, July and August 2004, when mortality reached 3 to $6 \%$.

Macroscopic observations of the affected fish showed darkening of the ventral skin (Fig. 1A), reddening at the base of the fins (Fig. 1B,C), and skin ulcers surrounded by a whitish halo (Fig. 1D). Some of these ulcers spread into muscular tissue, exposing the fin rays (Fig. 1E). A frequent clinical sign was the distension of the abdominal cavity, caused by an accumulation of ascitic fluid, which under light microscopic examination showed the presence of ciliates. Squash smears from skin and gills showed the presence of cil- iates in great numbers (50 to 100 ciliates per $10 \times$ field). Blood smears did not reveal the presence of ciliates.

Histological examination of infected fish gills showed hyperplasia and necrosis of the branchial tissue and the presence of ciliates in primary and secondary lamellae (Fig. 1F,G). Progressive destruction of skin layers and adjacent muscular tissue was observed in histological sections. Necrotic epidermal cells and subsequent epidermal desquamation were observed. Several ciliates and, in some cases, congestion of the blood vessels were found in the necrotic connective tissue of the stratus spongiosum of the dermis (Figs. 1I \& 2A,B). Haemorrhages, some ciliates and extensive myolisis were detected in skeletal muscle (Fig. 1I). An inflammatory response was not observed in any case. Histological analysis of the remaining collected organs (brain, heart, spleen, liver, kidney and intestine) did not reveal histopathological changes or the presence of the parasite.

The ciliates, ranging from 30 to $40 \mu \mathrm{m}$ in length and 18 to $20 \mu \mathrm{m}$ in width, were elongated and spindleshaped, with a rounded posterior and a tapered anterior end, with a contractile vacuole near the posterior end (Fig. 2C). A globular macronucleus and a small micronucleus were located in the middle of the body (Fig. 2D).

Somatic ciliature covered the entire body, comprising 11 to 14 ciliary rows (kineties) composed of dikinetids in the anterior two-thirds of the body (Fig. 2E). The ciliates presented a caudal cilium longer than the somatic ones (Fig. 2F). The citoproct was located at the end of a nonciliated director-meridian, which was positioned between the first and the last kineties (Fig. 2F) and beneath the buccal apparatus. The buccal apparatus was observed in the anterior half of the cell, and, although details of the oral ciliature were not completely discernible, it was possible to see, on the right side, a divided paraoral membrane (Fig. 2G).

\section{DISCUSSION}

From the results obtained in the present study it must be stated that turbot juveniles were very sensitive to the presence of scuticociliates, which caused the severe histopathological changes that seem to be responsible for mortality. The higher water temperatures probably caused the high mortalities observed during the summer months, since the life cycle of the parasite is affected by this parameter, with an optimal growth rate at $23^{\circ} \mathrm{C}$ (Iglesias et al. 2003). However, other factors could contribute to the high mortalities observed during this period.

Our results show a symptomatology consistent with previous reports of scuticociliatosis. However, in con- 

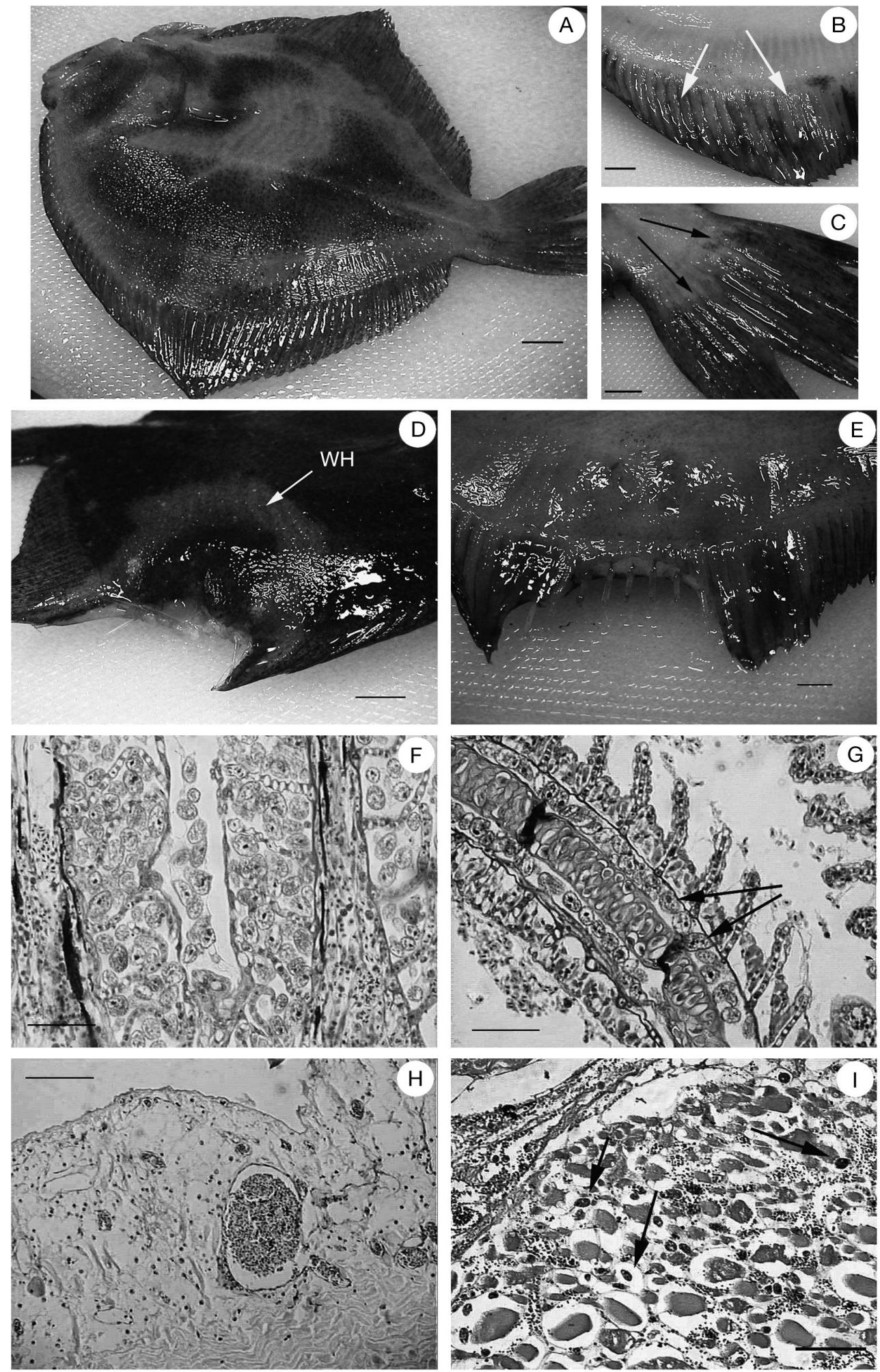

Fig. 1. Macroscopic and microscopic lesions associated with scuticociliatosis in turbot Scophthalmus maximus. (A) Extensive darkening of ventral skin; scale bar $=2 \mathrm{~cm}$. $(\mathrm{B}, \mathrm{C})$ Reddened lesions at the base of the fins (arrows); scale bar $=2 \mathrm{~cm}$. (D) Extensive skin ulcer with a surrounding whitish halo $(\mathrm{WH})$; scale bar $=1 \mathrm{~cm}$. (E) Erosion of the fin exposing the rays; scale bar $=1 \mathrm{~cm}$. (F) Hyperplasia and necrosis of branchial tissue and presence of ciliates in primary and secondary lamellae $(\mathrm{H} \& \mathrm{E})$; scale bar $=$ $50 \mu \mathrm{m}$. (G) Necrotic secondary lamellae and presence of ciliates in the primary lamellae (arrows) $(\mathrm{H} \& \mathrm{E}) ; \mathrm{scale}$ bar $=50 \mu \mathrm{m}$. (H) Congestion of a blood vessel of the stratum spongiosum of the dermis (H\&E); scale bar $=100 \mu$. (I) Presence of ciliates (arrows) and haemorrhages, and extensive myolisis of skeletal muscle (H\&E); scale bar $=100 \mu \mathrm{m}$ 

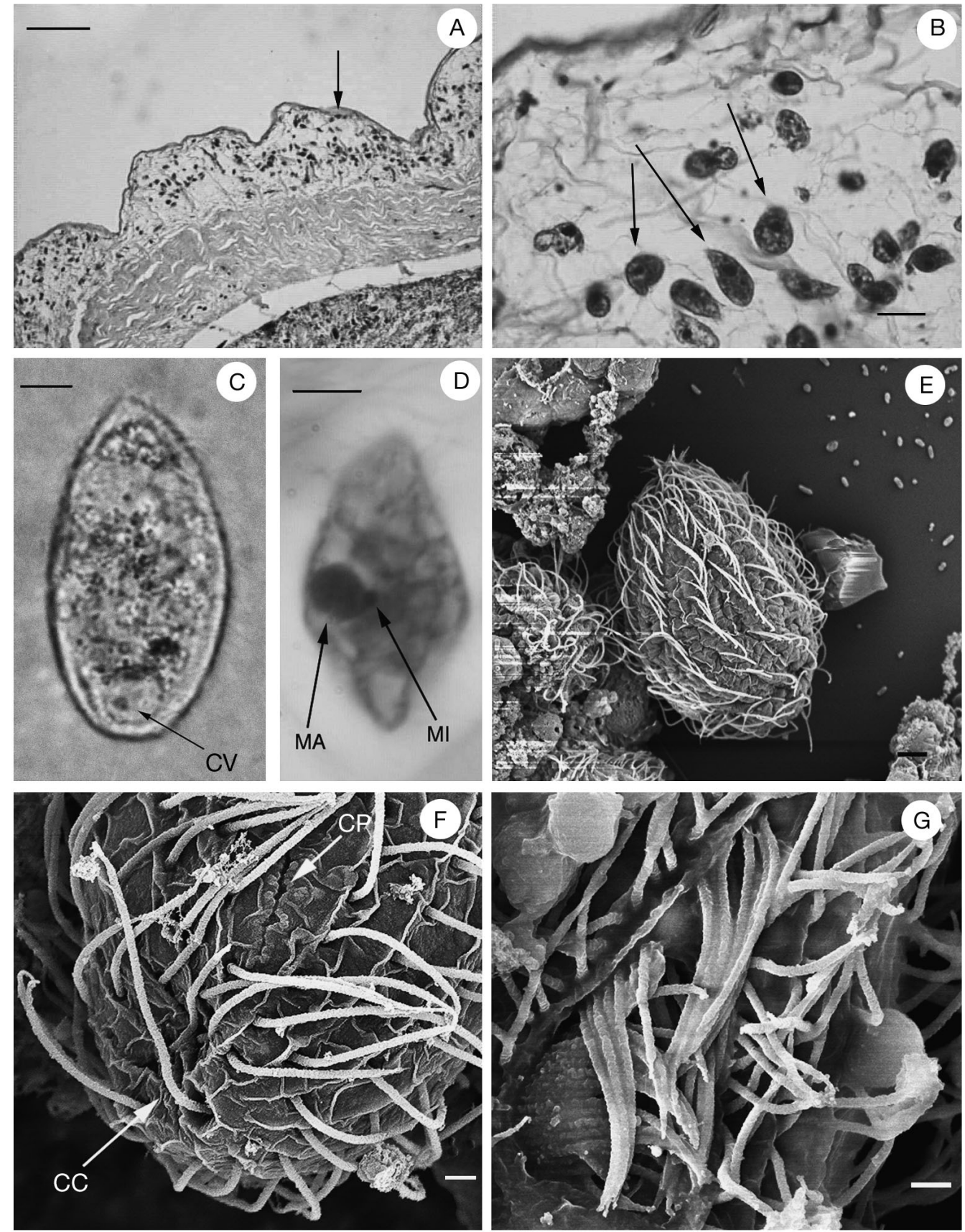

Fig. 2. Scuticociliates detected in turbot Scophthalmus maximus. (A) Epidermal desquamation and presence of ciliates (arrow) in the necrotic stratum spongiosum of the dermis $(\mathrm{H} \& \mathrm{E})$; scale bar $=200 \mu \mathrm{m}$. (B) Enlarged portion of the stratum spongiosum with ciliates $(\mathrm{H} \& \mathrm{E})$; scale bar $=20 \mu \mathrm{m}$. (C) Ciliate observed in a fresh mount showing a contractile vacuole $(\mathrm{CV})$; scale bar $=5 \mu \mathrm{m}$. (D) Histological section of the dermis showing the macro- (MA) and micronucleus (MI) of the scuticociliate (H\&E); scale bar = $5 \mu \mathrm{m}$. (E,F,G) Scanning electron micrographs of ciliates from skin mucus. (E) Somatic ciliature; scale bar $=3 \mu \mathrm{m}$. $(\mathrm{F}) \mathrm{Citoproct}(\mathrm{CP})$ and caudal cilium $(\mathrm{CC})$; scale bar $=1 \mu \mathrm{m}$. (G) Bucal apparatus, with a divided paroral membrane; scale bar $=1 \mu \mathrm{m}$

trast to some reports (Iglesias et al. 2001, Paramá et al. 2003), neither uni- nor bilateral exophthalmia was ever observed. The external lesions found in the present study were more extensive $(5$ to $7 \mathrm{~cm})$ than those described by Sterud et al. (2000).
To our knowledge, this is the first time such extensive lesions due to scuticociliates have been described in turbot. This may, at least partially, be explained by the presence of Gram-positive bacteria, identified as Streptococcus parauberis, in some fishes. 
Histological analysis of infected turbot revealed the presence of ciliates in the gills, skin and muscular tissue, which is in agreement with previous research (Dyková \& Figueras 1994, Iglesias et al. 2001, Jee et al. 2001, Paramá et al. 2003). Although parasites were observed in the abdominal ascitic fluid, the ciliate was never detected in peripheral blood, suggesting that, at least in this phase of invasion, the disease was not systemic. The presence of ciliates only in the gills, dermal and muscular layers suggests that the natural route of entry of the parasite could be through the skin or gill lesions, as hypothesised by Paramá et al. (2003).

The general features of the ciliates examined in the present study seem to suggest that they belong to the class Scuticociliatia, probably to the order Philasterida (Small 1967, Kwon et al. 2003), which has been described by several authors as comprising opportunistic and histophagous ciliate parasites.

The lesions found in the present study were more severe than those previously reported. It is plausible that the severity of the lesions presented here was due to a bacterial infection that may have aggravated the clinical condition of the fish. To our knowledge, this is the first time that scuticociliatosis in turbot has been described from Portugal. Considering that there is no effective treatment for scuticociliatosis, more attention needs to be given to prevention, through management practices and regular surveys.

\section{LITERATURE CITED}

Alvarez-Pellitero P, Palenzuela O, Padrós F, Sitjà-Bobadilha A, Riaza A, Silva R, Arán J (2004) Histophagous scuticociliatids (Ciliophora) parasitizing turbot Scophthalmus maximus: morphology, in vitro culture and virulence. Folia Parasitol 51:177-187

Cawthorn RJ (1997) Overview of 'Bumper car disease' impact on the North American lobster fishery. Int J Para-

Editorial responsibility: Dieter Steinhagen,

Hannover, Germany sitol 27:167-172

Dyková I, Figueras A (1994) Histopathological changes in turbot Scophtalmus maximus due to a histophagous ciliate. Dis Aquat Org 18:5-9

Iglesias R, Parama A, Alvarez MF, Leiro J, Fernandez J, Sanmartin ML (2001) Philasterides dicentrarchi (Ciliophora, Scuticociliatida) as the causative agent of scuticociliatosis in farmed turbot Scophthalmus maximus in Galicia (NW Spain). Dis Aquat Org 46:47-55

Iglesias R, Parama A, Alvarez MF, Leiro J, Sanmartin ML (2002) Antiprotozoals effective in vitro against the scuticociliate fish pathogen Philasterides dicentrarchi. Dis Aquat Org 49:191-197

Iglesias R, Parama A, Alvarez MF, Leiro J, Aja C, Sanmartin ML (2003) In vitro growth requirements for the fish pathogen Philasterides dicentrarchi (Ciliophora, Scuticociliatida). Vet Parasitol 111:19-30

Jee BY, Kim YC, Park MS (2001) Morphology and biology of parasite responsible for scuticociliatosis of cultured olive flounder Paralichthys olivaceus. Dis Aquat Org 47: $49-55$

Kim SM, Cho JB, Kim SK, Nam YK, Kim KH (2004a) Occurrence of scuticociliatosis in olive flounder Paralichthys olivaceus by Phiasterides dicentrarchi (Ciliophora: Scuticociliatida). Dis Aquat Org 62:233-238

Kim SM, Cho JB, Lee EH, Kwon SR, Kim SK, Nam YK, Kim $\mathrm{KH}$ (2004b) Pseudocohnilembus persalinus (Ciliophora: Scuticociliatida) is an additional species causing scuticociliatosis in olive flounder Paralichthys olivaceus. Dis Aquat Org 62:239-244

Kwon SR, Kim CS, Kim KH (2003) Differences between shortand long-term cultures of Uronema marinum (Ciliophora, Scuticociliatida) in chemiluminescence inhibitory activity, antioxidative enzyme and protease activity. Aquaculture 221:107-114

Paramá A, Iglesias R, Álvarez MF, Leiro J, Aja C, Sanmartín ML (2003) Philasterides dicentrarchi (Ciliophora, Scuticociliatida): experimental infection and possible routes of entry in farmed turbot (Scophthalmus maximus). Aquaculture 217:73-80

Small EB (1967) The Scuticociliatida, a new order of the class Ciliatea (phylum Protozoa, subphylum Ciliophora). Trans Am Microsc Soc 86:345-370

Sterud E, Hansen MK, Mo TA (2000) Systemic infection with Uronema-like ciliates in farmed turbot, Scophthalmus maximus (L.). J Fish Dis 23:33-37

Submitted: March 9, 2006; Accepted: November 16, 2006

Proofs received from author(s): February 28, 2007 